\title{
Analisis Ekonomi Pemilihan Electric Submersible Pump Pada Beberapa Vendor
}

\author{
Economic Analysis of Electric Submersible Pump Selection \\ on Multiple Vendors \\ Muhammad Ariyon \\ Jurusan Teknik Perminyakan Fakultas Teknik Universitas Islam Riau \\ Jl. Kaharuddin Nasution 113 Pekanbaru-28284 \\ ariyon_pku@yahoo.com
}

\begin{abstract}
Abstrak
Tulisan ini memuat bahasan tentang pemilihan Electric Submersible Pump berdasarkan perhitungan analisa keekonomian pada beberapa vendor. Pemilihan dilakukan dengan menghitung indikator keuntungan berupa Internal Rate of Return (IRR), Net Present Value (NPV), Benefit to Cost Ratio (B/C), Pay Out Time (POT) untuk menentukan nilai keekonomian dan kelayakan pompa ESP pada masing-masing vendor. Hasil perhitungan indikator keuntungan untuk Pompa 1 (Centraleft) adalah IRR = 16,24 \% NPV@ i =5 \%= 654,250 US\$; B/C = 1,2; POT = 3,8 tahun; untuk Pompa 2 (Motherford) adalah IRR = 9,09 $\%$ NPV@ $\mathrm{i}=5 \%=288,370 \mathrm{US} \$$; B/C = 1,11; POT = 4,1 tahun; untuk Pompa 3 (Red-A) adalah IRR = 21,21 \% NPV@ $\mathrm{i}=5 \%=854,250 \mathrm{US} \$ ; \mathrm{B} / \mathrm{C}=1,28 ; \mathrm{POT}=3,3$ tahun; dan untuk Pompa 4 (Wooden Group) adalah IRR=12,86\% NPV@ i =5\%=355,430 US\$; B/C $=1,16 ;$ POT $=4$ tahun. Hal tersebut menunjukkan bahwa pompa ketiga (Red-A) memiliki indikator keuntungan paling tinggi diantara kompetitor lainnya, sehingga dianggap paling menguntungkan bila ditinjau berdasarkan perhitungan analisis keekonomian.
\end{abstract}

Kata-kata kunci : Analisa keekonomian, Electric Submersible Pump, Internal Rate of Return (IRR), Net Present Value (NPV), Benefit to Cost Ratio (B/C)

\begin{abstract}
This paper contains a discussion of Electric Submersible Pump selection is based on the calculation of the economic analysis on multiple vendors. The selection is done by calculating the profit indicator in the form of the Internal Rate of Return (IRR), Net Present Value (NPV), Benefit to Cost Ratio (B / C), Pay Out Time (POT) to determine the economic value and feasibility of ESP pumps on each vendors. The results of the calculation of profit indicator for Pump 1 (Centraleft) is IRR = 16.24\% NPV @ $\mathrm{i}=5 \%=654.250 \mathrm{US} \$$; B $/ \mathrm{C}=1.2$; POT $=3.8$ years; for Pump 2 (Motherford) is the NPV IRR =9.09\% @ i = 5\% $=288.370$ US \$; B / C = 1.11 ; POT $=4.1$ years; for Pump 3 (Red-A) is $21.21 \%$ NPV IRR $=@ \mathrm{i}=5 \%=854.250$ US \$; $\mathrm{B} / \mathrm{C}=1.28$; $\mathrm{POT}=3.3$ years; and for Pump 4 (Wooden Group) is IRR $=12.86 \%$ NPV @ $\mathrm{i}=$ $5 \%=355.430$ US \$; $\mathrm{B} / \mathrm{C}=1.16$; POT $=4$ years. This shows that the third pump (Red-A) has the highest profit indicator among other competitors, so it is considered most beneficial when the review is based on the calculation of economic analysis.
\end{abstract}

Key words: Analysis of the economic, Electric Submersible Pump, Internal Rate of Return (IRR), Net Present Value (NPV), Benefit to Cost Ratio (B / C) 


\section{PENDAHULUAN}

Industri Migas merupakan industri yang memiliki resiko bisnis yang sangat tinggi (High Risk). Untuk menilai layak atau tidaknya suatu kontrak pada pengusahaan dan pengembangan migas seperti pada pemilihan (ESP) Electric Submersible Pump, perlu ditentukan beberapa faktor yang menunjukkan untung atau tidaknya jika pompa ESP tersebut dipegang oleh suatu vendor tertentu. Faktorfaktor ini disebut sebagai indikator keuntungan (profit indicator). Indikator keuntungan yang biasa digunakan dalam industri migas adalah Net Present Value (NPV), Internal Rate of Return (IRR), , Benefit to Cost (B/C), Pay Out Time (POT). Suatu perusahaan akan melakukan investasi bila IRR-nya lebih besar dari Minimum Atractive of Return (MARR). Untuk benyak alternatif diperlukan tes lebih lanjut bila hasil pemilihan alternatif berdasarkan NPV tidak sesuai dengan hasil berdasarkan hasil IRR. Parameter-parameter ini umunya bersifat obyektif terhadap penilaian tingkat kelayakan suatu proyek investasi komersial. Selain itu dapat digunakan juga sebagai informasi yang cukup objektif bagi proses pengambilan keputusan atau bahan pertimbangan terhadap kebijaksanaan untuk meningkatkan kapasitas produksi lapangan dan jumlah proyek-proyek investasi lebih lanjut.
Tulisan ini memuat bahasan tentang pemilihan Electric Submersible Pump berdasarkan perhitungan analisa keekonomian pada beberapa vendor. Pemilihan dilakukan dengan menghitung indikator keuntungan berupa Internal Rate of Return (IRR), Net Present Value (NPV), Benefit to Cost Ratio (B/C), Pay Out Time (POT) untuk menentukan nilai keekonomian dan kelayakan pompa ESP pada masing-masing vendor

\section{METODOLOGI PENELITIAN}

Metode yang dilakukan pada penelitian ini meliputi kegiatan terstruktur mulai dari melakukan studi literatur, mempersiapkan data, mengolah data, menghitung indikator keekonomian pada masing-masing vendor ESP, kemudian menganalisa hasil perhitungan indikator keuntungan tersebut dan menentukan pompa ESP dari vendor mana yang paling menguntungkan.

\section{HASIL DAN PEMBAHASAN}

Indikator yang menjadi penilaian keuntungan meliputi: Net Present Value, NPV (nilai sekarang), Internal Rate of Return, IRR (laju tingkat pengembalian, Benefit to Cost, B/C (keuntungan tiap dollar yang ditanamkan), Pay Out Time, POT (waktu pengembalian modal) 
Nilai investasi dan Cash Flow masingmasing vendor untuk jangka waktu kontrak 5 tahun adalah seperti yang tercantum dalam tabel 1

Tabel 1

\begin{tabular}{|r|c|c|c|}
\hline Centraleft & Motherford & \multicolumn{1}{c|}{ Red -A } & \multicolumn{1}{c|}{ Wooden } \\
\hline$(3.200 .000)$ & $(2.700 .000)$ & $(3.000 .000)$ & $(2.200 .000)$ \\
\hline 700.000 & 500.000 & 700.000 & 400.000 \\
\hline 800.000 & 600.000 & 800.000 & 500.000 \\
\hline 900.000 & 700.000 & 900.000 & 600.000 \\
\hline 1.000 .000 & 800.000 & 1.000 .000 & 700.000 \\
\hline 1.100 .000 & 900.000 & 1.100 .000 & 800.000 \\
\hline
\end{tabular}

Jangka waktu kontrak 5 tahun dengan nilai $\operatorname{MARR}=5 \%$.

III.1.Perhitungan

Keuntungan Alternatif 1 (Pompa Centraleft)

a. Net Present Value (NPV)

\begin{tabular}{|c|r|}
\hline Tahun & Aliran Dana (\$) \\
\hline \hline 0 & $(3.200 .000)$ \\
\hline 1 & 700.000 \\
\hline 2 & 800.000 \\
\hline 3 & 900.000 \\
\hline 4 & 1.000 .000 \\
\hline 5 & 1.100 .000 \\
\hline
\end{tabular}

Net Present Value (NPV) diperoleh melalui persamaan :

$$
\begin{aligned}
& N P V=\left[\sum_{t=0}^{n} \frac{C F t}{(1+i)^{t}}\right]-I_{0} \quad \text { atau } \\
& N P V=C F_{0}+C F_{1}(\mathrm{P} / \mathrm{F}, 5 \%, 1)+ \\
& C F_{2}(\mathrm{P} / \mathrm{F}, 5 \%, 2)+ \\
& C F_{3}(\mathrm{P} / \mathrm{F}, 5 \%, 3)+ \\
& C F_{4}(\mathrm{P} / \mathrm{F}, 5 \%, 4)+ \\
& C F_{5}(\mathrm{P} / \mathrm{F}, 5 \%, 5)
\end{aligned}
$$

$$
\begin{aligned}
= & -3,200,000+700,000 \\
& (0,9524)+800,000(0,9070) \\
& +900,000(0,8638)+ \\
1,000,000 \quad(0,8227)+ & + \\
1,100,000(0,7835) &
\end{aligned}
$$$$
N P V=\quad 654,250
$$

b. Internal Rate of Return (IRR) diperoleh apabila NPV $=0$ melalui trial and error sebagai berikut :

- Misalnya pada $\mathrm{i}=5 \%$ diperoleh NPV $=654,250$; kemudian dicoba dengan nilai $\mathrm{i}=8$ $\%$, dengan cara yang sama diperoleh nilai NPV $=-487,840$;

- Dari kedua nilai NPV tersebut dapat diketahui bahwa nilai IRR berada pada kisaran 654,250 > IRR > 487,840 ;

- Melakukan interpolasi terhadap kisaran nilai IRR diatas dengan gambaran sebagai berikut :

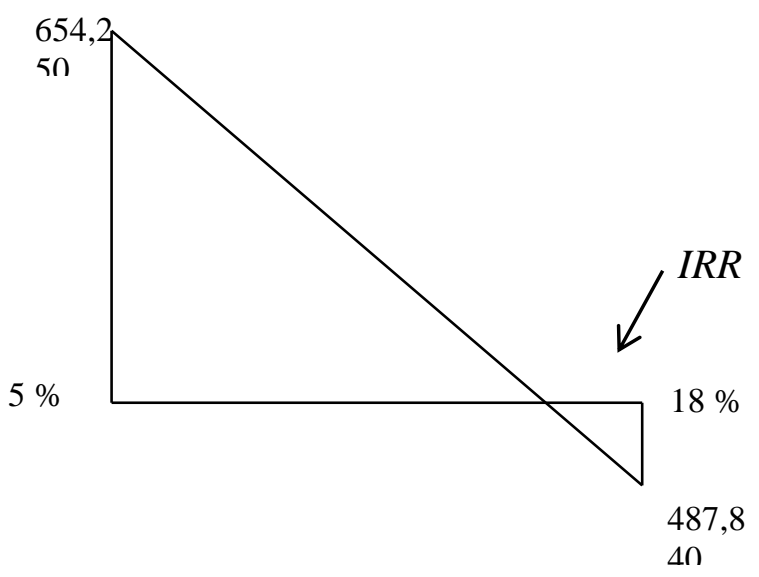




$$
\begin{array}{ll}
I R R=5 \%+(18 \%-5 \%)\left\{\frac{654,250}{654,250+487,840}\right\} & \text { POT }=3+(4-3)\left(\frac{800000}{800000+200000}\right) \\
I R R=5 \%+13 \%(0,573) & \text { POT }=3+0,8 \\
I R R=5 \%+7,477 \% & \text { POT }=3,8 \text { th } \\
I R R=12,477 \% &
\end{array}
$$

c. B/C diperoleh dari persamaan $P W_{B}$ pada $\operatorname{MARR}=5 \% / I$,

Dimana : $P W_{B}$ adalah Present

Worth Benefit dan I adalah Investasi

$P W_{B}$ pada MARR $=5 \%$ pada tabel Proyek A diatas adalah penjumlahan nilai $D C F$ dari tahun ke-1 sampai tahun ke-5, yaitu sebesar 3,854,250 sedangkan investasinya adalah tahun ke-0 sebesar 3,200,000, dengan demikian nilai $B / C$ adalah :

$$
B / C=\frac{P W_{B}}{C}=\frac{3,854,250}{3,200,000}=1,2
$$

d. Pay Out Time (POT) atau Periode Pengembalian.

\begin{tabular}{|r|r|r|}
\hline Tahun & Aliran Dana (\$) & Komulatif (\$) \\
\hline \hline 0 & $(3.200 .000)$ & $(3.200 .000)$ \\
\hline 1 & 700.000 & $(2.500 .000)$ \\
\hline 2 & 800.000 & $(1.700 .000)$ \\
\hline 3 & 900.000 & $(800.000)$ \\
\hline 4 & 1.000 .000 & 200.000 \\
\hline 5 & 1.100 .000 & 1.300 .000 \\
\hline
\end{tabular}

Dari tabel terlihat bahwa periode pengembalian adalah antara tahun ke-3 dan tahun ke-4. Dengan cara interpolasi periode pengembalian dapat ditentukan sebagai berikut :
Pay Out Time (POT) atau Periode Pengembalian dari Proyek A adalah 3,8

\section{Tahun}

III.2.Perhitungan

Indikator

Keuntungan Alternatif 2 (Pompa Centraleft)

a. Net Present Value (NPV)

\begin{tabular}{|r|r|}
\hline 0 & $(2.700 .000)$ \\
\hline 1 & 500.000 \\
\hline 2 & 600.000 \\
\hline 3 & 700.000 \\
\hline 4 & 800.000 \\
\hline 5 & 900.000 \\
\hline
\end{tabular}

Net Present Value (NPV) diperoleh melalui persamaan : $N P V=\left[\sum_{t=0}^{n} \frac{C F t}{(1+i)^{t}}\right]-I_{0} \quad$ atau

$$
\begin{aligned}
N P V= & C F_{0}+C F_{1}(\mathrm{P} / \mathrm{F}, 5 \%, 1)+ \\
& C F_{2}(\mathrm{P} / \mathrm{F}, 5 \%, 2)+ \\
& C F_{3}(\mathrm{P} / \mathrm{F}, 5 \%, 3)+ \\
& C F_{4}(\mathrm{P} / \mathrm{F}, 5 \%, 4)+ \\
& C F_{5}(\mathrm{P} / \mathrm{F}, 5 \%, 5) \\
= & -2,700,000+500,000 \\
& (0,9524)+600,000(0,9070) \\
& +700,000 \quad(0,8638)+ \\
& 800,000(0,8227)+900,000 \\
& (0,7835)
\end{aligned}
$$

$N P V=288,370$ 
b. Internal Rate of Return (IRR) diperoleh apabila NPV $=0$ melalui trial and error sebagai berikut :

- Misalnya pada $i=5 \%$ diperoleh $\mathrm{NPV}=288,370 ;$ kemudian dicoba dengan nilai $\mathrm{i}=12 \%$, dengan cara yang sama diperoleh nilai NPV = 257,910

- Dari kedua nilai NPV tersebut dapat diketahui bahwa nilai IRR berada pada kisaran 288,370 > IRR > 257,910 ;

- Melakukan interpolasi terhadap kisaran nilai IRR diatas dengan gambaran sebagai berikut :

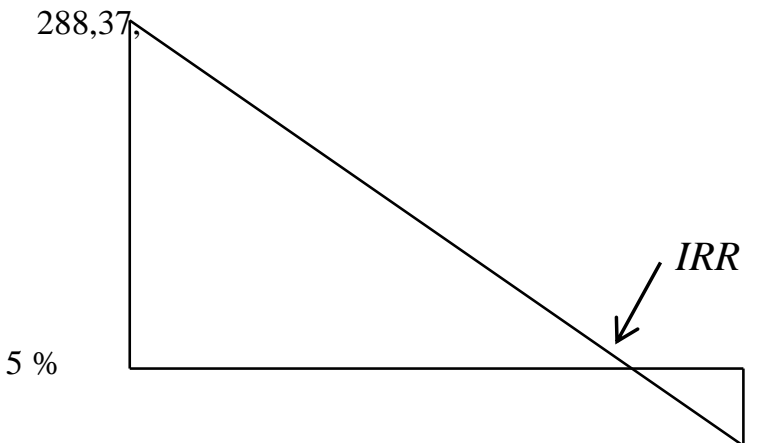

Dimana $\quad P W_{B}$ adalah Present Worth Benefit dan I adalah Investasi $P W_{B}$ pada MARR $=5 \%$ pada tabel Proyek A diatas adalah penjumlahan nilai $D C F$ dari tahun ke-1 sampai tahun ke-5, yaitu sebesar 2,988,370 sedangkan investasinya adalah tahun ke-0 sebesar 2,700,000, dengan demikian nilai $B / C$ adalah :

$$
B / C=\frac{P W_{B}}{C}=\frac{2,988,370}{2,700,000}=1,11
$$

d. Pay Out Time (POT) atau Periode Pengembalian.

\begin{tabular}{|r|r|r|}
\hline 0 & $(2.700 .000)$ & $(2.700 .000)$ \\
\hline 1 & 500.000 & $(2.200 .000)$ \\
\hline 2 & 600.000 & $(1.600 .000)$ \\
\hline 3 & 700.000 & $(900.000)$ \\
\hline 4 & 800.000 & $(100.000)$ \\
\hline 5 & 900.000 & 800.000 \\
\hline
\end{tabular}

Dari tabel terlihat bahwa periode pengembalian adalah antara tahun ke-4 dan tahun ke-5. Dengan cara interpolasi periode pengembalian dapat ditentukan sebagai berikut :

$$
\begin{aligned}
& P O T=4+(5-4)\left(\frac{100000}{100000+800000}\right) \\
& P O T=4+0,1 \\
& P O T=4,1 \text { th }
\end{aligned}
$$

Pay Out Time (POT) atau Periode Pengembalian dari Proyek A adalah 4,1

Tahun.

c. B/C diperoleh dari persamaan $P W_{B}$ pada $\operatorname{MARR}=5 \% / I$, 
III.3. Perhitungan

Indikator

Keuntungan Alternatif 3 (Pompa

\section{Centraleft)}

a. Net Present Value (NPV)

\begin{tabular}{|c|r|}
\hline Tahun & Aliran Dana (\$) \\
\hline \hline 0 & $(3.000 .000)$ \\
\hline 1 & 700.000 \\
\hline 2 & 800.000 \\
\hline 3 & 900.000 \\
\hline 4 & 1.000 .000 \\
\hline 5 & 1.100 .000 \\
\hline
\end{tabular}

Net Present Value (NPV) diperoleh melalui persamaan :

$$
\begin{aligned}
& N P V=\left[\sum_{t=0}^{n} \frac{C F t}{(1+i)^{t}}\right]-I_{0} \quad \text { atau } \\
& N P V= C F_{0}+C F_{1}(\mathrm{P} / \mathrm{F}, 5 \%, 1)+ \\
& C F_{2}(\mathrm{P} / \mathrm{F}, 5 \%, 2)+ \\
& C F_{3}(\mathrm{P} / \mathrm{F}, 5 \%, 3)+ \\
& C F_{4}(\mathrm{P} / \mathrm{F}, 5 \%, 4)+ \\
& C F_{5}(\mathrm{P} / \mathrm{F}, 5 \%, 5) \\
&=-3,000,000 \quad+ \\
&(0,9524)+800,000(0,9070) \\
&+\quad 900,000 \quad(0,8638)+ \\
& 1,000,000 \quad(0,8227) \\
& 1,100,000(0,7835) \\
& \boldsymbol{N P V}= \mathbf{8 5 4}, \mathbf{2 5 0} \quad
\end{aligned}
$$

b. Internal Rate of Return (IRR) diperoleh apabila NPV $=0$ melalui trial and error sebagai berikut :

- Misalnya pada i = $5 \%$ diperoleh $\mathrm{NPV}=854,250 ;$ kemudian dicoba dengan nilai $\mathrm{i}=18 \%$, dengan cara yang sama diperoleh nilai NPV = 287,840

- Dari kedua nilai NPV tersebut dapat diketahui bahwa nilai IRR berada pada kisaran $854,250>$ IRR > 287,840 ;

- Melakukan interpolasi terhadap kisaran nilai IRR diatas dengan gambaran sebagai berikut :

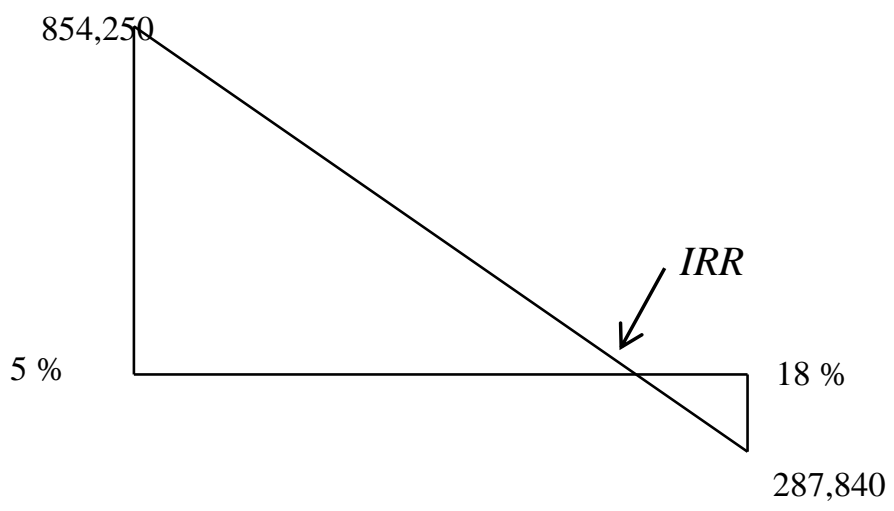

$$
\begin{aligned}
& I R R=5 \%+(18 \%-5 \%)\left\{\frac{854,250}{854,250+287,840}\right\} \\
& I R R=5 \%+13 \%(0,75) \\
& I R R=5 \%+9,72 \% \\
& I R R=14,72 \%
\end{aligned}
$$

c. $\mathrm{B} / \mathrm{C}$ diperoleh dari persamaan $P W_{B}$ pada $\operatorname{MARR}=5 \% / I$,

Dimana $: P W_{B}$ adalah Present Worth Benefit dan I adalah Investasi $P W_{B}$ pada MARR $=5 \%$ pada tabel Proyek A diatas adalah penjumlahan nilai $D C F$ dari tahun ke-1 sampai tahun ke-5, yaitu sebesar 3,854,250 sedangkan investasinya 
adalah tahun ke-0 sebesar 3,000,000, dengan demikian nilai $B / C$ adalah :

$B / C=\frac{P W_{B}}{C}=\frac{3,854,250}{3,000,000}=1,28$

d. Pay Out Time (POT) atau Periode Pengembalian.

\begin{tabular}{|c|r|r|}
\hline Tahun & Aliran Dana (\$) & \multicolumn{1}{|c|}{ Komulatif $\mathbf{( \$ )}$} \\
\hline \hline 0 & $(3.200 .000)$ & $(3.000 .000)$ \\
\hline 1 & 700.000 & $(2.300 .000)$ \\
\hline 2 & 800.000 & $(1.500 .000)$ \\
\hline 3 & 900.000 & $(600.000)$ \\
\hline 4 & 1.000 .000 & 400.000 \\
\hline 5 & 1.100 .000 & 1.500 .000 \\
\hline
\end{tabular}

Dari tabel terlihat bahwa periode pengembalian adalah antara tahun ke-3 dan tahun ke-4. Dengan cara interpolasi periode pengembalian dapat ditentukan sebagai berikut :

$$
\begin{aligned}
& P O T=3+(4-3)\left(\frac{600000}{600000+400000}\right) \\
& P O T=3+0,6 \\
& P O T=3,6 \text { th }
\end{aligned}
$$

Pay Out Time (POT) atau Periode Pengembalian dari Proyek A adalah 3,6 Tahun.

\section{III.4. Perhitungan}

Indikator

Keuntungan Alternatif 4 (Pompa Centraleft)

a.Net Present Value (NPV)

\begin{tabular}{|c|r|}
\hline Tahun & Aliran Dana (\$) \\
\hline \hline 0 & $(2.200 .000)$ \\
\hline 1 & 400.000 \\
\hline 2 & 500.000 \\
\hline 3 & 600.000 \\
\hline 4 & 700.000 \\
\hline 5 & 800.000 \\
\hline
\end{tabular}

Net Present Value (NPV) diperoleh melalui persamaan :

$$
\begin{aligned}
& N P V=\left[\sum_{t=0}^{n} \frac{C F t}{(1+i)^{t}}\right]-I_{0} \quad \text { atau } \\
& N P V= C F_{0}+C F_{1}(\mathrm{P} / \mathrm{F}, 5 \%, 1)+ \\
& C F_{2}(\mathrm{P} / \mathrm{F}, 5 \%, 2)+ \\
& C F_{3}(\mathrm{P} / \mathrm{F}, 5 \%, 3)+ \\
& C F_{4}(\mathrm{P} / \mathrm{F}, 5 \%, 4)+ \\
& C F_{5}(\mathrm{P} / \mathrm{F}, 5 \%, 5) \\
&=-2,200,000 \quad+ \\
&(0,9524)+500,000(0,9070) \\
&+\quad 600,000 \quad(0,8638)+ \\
& 700,000(0,8227)+800,000 \\
&(0,7835)
\end{aligned}
$$

$$
N P V=355,430
$$

b. Internal Rate of Return (IRR) diperoleh apabila NPV $=0$ melalui trial and error sebagai berikut :

- Misalnya pada $\mathrm{i}=5 \%$ diperoleh NPV = 355,430; kemudian dicoba dengan nilai $\mathrm{i}=12 \%$, dengan cara yang sama diperoleh nilai NPV $=-118,390$;

- Dari kedua nilai NPV tersebut dapat diketahui bahwa nilai IRR berada pada kisaran 355,430 > IRR > -118,390 ; 
- Melakukan interpolasi terhadap kisaran nilai IRR diatas dengan gambaran sebagai berikut :

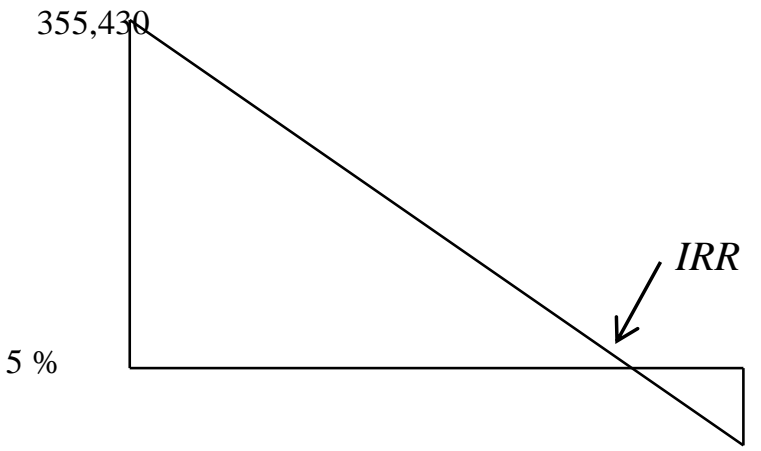

Dari tabel terlihat bahwa periode pengembalian adalah tahun ke-4.

118,390

\begin{tabular}{|c|c|c|}
\hline Tahun & Aliran Dana (\$) & nulatif (\$) \\
\hline 0 & $(2.200 .000)$ & $(2.200 .000)$ \\
\hline 1 & 400.000 & $(1.800 .000)$ \\
\hline 2 & 500.000 & $(1.300 .000)$ \\
\hline 3 & 600.000 & (700.000) \\
\hline 4 & 700.000 & - \\
\hline 5 & 800.000 & 800.000 \\
\hline
\end{tabular}

d. Pay Out Time (POT) atau Periode Pengembalian.

$$
\begin{aligned}
& I R R=5 \%+(12 \%-5 \%)\left\{\frac{355,430}{355,430+118,390}\right\} \\
& I R R=5 \%+7 \%(0,75) \\
& I R R=5 \%+5,25 \% \\
& I R R=10,525 \%
\end{aligned}
$$

\section{III.5 Perbandingan Indikator}

\section{Keuntungan Masing-masing Vendor Pompa}

Tabel 2

Perbandingan Indikator Keuntungan Masing-masing Vendor

c. $\mathrm{B} / \mathrm{C}$ diperoleh dari persamaan $P W_{B}$ pada $\operatorname{MARR}=5 \% / I$,

Dimana $\quad P W_{B}$ adalah Present

Worth Benefit dan I adalah Investasi

$P W_{B}$ pada MARR $=5 \%$ pada tabel Proyek A diatas adalah penjumlahan nilai $D C F$ dari tahun ke-1 sampai tahun ke-5, yaitu sebesar 2,555,430 sedangkan investasinya adalah tahun ke-0 sebesar 2,200,000, dengan demikian nilai $B / C$ adalah :

$$
B / C=\frac{P W_{B}}{C}=\frac{2,555,430}{2,200,000}=1,16
$$

\begin{tabular}{|l|r|r|r|r|}
\hline Indikator & \multicolumn{4}{|c|}{ VENDOR POMPA ESP } \\
\hline Keuntungan & \multicolumn{1}{c|}{ Pompa 1 } & Pompa 2 & Pompa 3 & \multicolumn{1}{c|}{ Pompa 4 } \\
\cline { 2 - 5 } & Centraleft & Motherford & Red-A & Wooden G \\
\hline \hline Invest (\$) & $3,200,000$ & $2,700,000$ & $3,000,000$ & $2,200,000$ \\
\hline NPV (\$) & 654,25 & 288,37 & 854,25 & 355,43 \\
\hline IRR (\%) & 12,477 & 8,69 & 14,72 & 10,52 \\
\hline B/C & 1,2 & 1,11 & 1,28 & 1,16 \\
\hline POT thn $)$ & 3,8 & 4,1 & 3,3 & 4 \\
\hline
\end{tabular}

Berdasarkan tabel tersebut dapat diketahui bahwa pompa 3 (Red-A) memiliki indikator keuntungan paling tinggi diantara kompetitor lainnya 


\section{KESIMPULAN}

Berdasarkan hasil penelitian yang penulis lakukan dapat disimpulkan sebagai berikut:

1. Hasil perhitungan indikator keuntungan untuk Pompa 1 (Centraleft) adalah IRR $=16,24 \%$ NPV@i $@ \%=654,250$ US\$; $\mathrm{B} / \mathrm{C}=1,2 ; \mathrm{POT}=3,8$ tahun

2. Hasil perhitungan indikator keuntungan untuk Pompa 2 (Motherford) adalah IRR $=9,09 \%$ NPV@ $\mathrm{i}=5 \%=288,370$ US\$; $\mathrm{B} / \mathrm{C}=1,11 ; \mathrm{POT}=4,1$ tahun

3. Hasil perhitungan indikator keuntungan untuk Pompa 3 (RedA) adalah IRR = 21,21\% NPV@ i $=5 \%=854,250 \mathrm{US} \$ \mathrm{~B} / \mathrm{C}=1,28$ ; $\mathrm{POT}=3,3$ tahun

4. Hasil perhitungan indikator keuntungan untuk Pompa 4 (Wooden Group) adalah IRR = $12,86 \%$ NPV@i=5 \% = 355,430 $\mathrm{US} \$ ; \mathrm{B} / \mathrm{C}=1,16 ; \mathrm{POT}=4$ tahun.

5. Berdasarkan hasil perhitungan tersebut, pompa ketiga (Red-A) memiliki indikator keuntungan paling tinggi diantara kompetitor lainnya, sehingga dianggap paling menguntungkan bila ditinjau berdasarkan perhitungan analisis keekonomian.

\section{DAFTAR PUSTAKA}

Allen H. Fraser and Seba D. Richard, "Economics of Worldwide Petroleum Production", Oil \& Gas Consultans International, Inc., Tulsa, Oklahoma, 1993.

Allinson Guy, "Economics of Petroleum Exploration and Production", Program Diklat Tim Pengelolaan IWPL Migas Bekerja Sama dengan IAGI, Juni, 1992.

Ardiansyah, Ir., 2007, Artificial Lift, Classroom Presentation Theory, Baker Hughes, Inc. - Centrilift, Duri, Riau

Brown, E., Kermit, April 1993, The Technology of Artificial Lift Metods, The University Of Tulsa, Oklahoma Haas, Rainer Dr. \& Meixner, Oliver Dr., 2008, Institute of Marketing \& Innovation, University of Natural Resources and Applied Life Sciences, Vienna, Austria

Newendrop D. Paul, Decision Analysis for Petroleum Exploration, PennWell Publishing Company, Tulsa Oklahoma, Maret, 1975.

Partowidagdo Widjajono, Manajemen dan Ekonomi Minyak dan Gas Bumi, Program Studi Pembangunan Program Pasca Sarjana ITB, Bandung, 2002 
Satter Abdus, Ph. D. dan Ganesh C. Thakur, Ph. D., Integrated Petroleum Reservoir Management, Penn Well

Publishing Company, Tulsa

Oklahoma,1994 
Journal of Earth Energy Engineering

ISSN: $2301-8097$ Jurusan Teknik Perminyakan - UIR 